\title{
Uso del videomarketing en tiempos de la Covid19: estrategias del sector de la moda
}

\section{Use of video marketing in times of Covid19: strategies of the fashion sector}

\author{
Torre Reverte, Berta ${ }^{1}$, Girotto, Michele*1 \\ 1 Departamento de Empresas, Facultad de Economía y Empresa, Universidad de Barcelona \\ Girotto, Michele. michele.girotto@ub.edu
}

\section{Resumen}

La consolidación de plataformas con capacidad para desarrollo de contenidos de video ha impulsado de manera significativa la manera cómo las marcas de moda trabajan sus estrategias de comunicación. Este artículo tiene el objetivo de profundizar en el conocimiento de las estrategias de contenido digital desarrollado por las marcas de moda, buscando identificar tres aspectos principales: las plataformas digitales más populares donde las marcas emplean videomarketing, según la categoría de su posicionamiento; qué diferencias existen en tipologías de videos y mensajes; y qué tendencias de contenidos de videos han surgido durante la pandemia de la Covid19. Para esta finalidad, este estudio emplea un análisis de contenido aplicado a las redes sociales de cuatro marcas de moda posicionadas en las categorías de lujo y de moda accesible durante el periodo de confinamiento provocado por la pandemia de la Covid19. El artículo pone en evidencia que los contenidos de marca en formato de vídeo son menos utilizados en comparación con los formatos de texto e imágenes publicados en plataformas online, y discute las principales diferencias en las técnicas de videomarketing utilizadas y las más importantes innovaciones en las respuestas de las marcas.

Palabras clave: videomarketing, branded content, marketing digital, fashion brands, comunicación publicitaria.

\begin{abstract}
The consolidation of platforms with the capacity to develop video content has significantly boosted the way fashion brands develop their communication strategies. This article aims to expand the knowledge of digital content strategies carried out by fashion brands, seeking to identify three main aspects: the most popular digital platforms brands use for video marketing according to their positioning category, what trends in video content have emerged during the Covid19 pandemic and what differences in types of videos and messages brands seek to transmit in the content of their videos. For this purpose, this study uses a content analysis applied to the social networks of four fashion brands positioned in the categories of luxury and accessible fashion during the period of the Covid19 pandemic lockdown. The article depicts that brand content in video format is still lower when compared to the use of text and image formats published on online platforms, and discusses the main differences in the video marketing techniques adopted and the main innovations in brand responses.
\end{abstract}

Key words: video marketing, branded content, digital marketing, fashion brands, advertising communication.

DOI 10.46588/invurnus.v16i1.36

Recibido 14/09/2021

Aceptado 01/12/2021

Publicado 02/12/2021 


\section{Introducción}

Según el informe de We are social y Hootsuite (2021), más de 37 millones de personas en España usan las redes, lo que supone un $80 \%$ de la población; además, acceden a ellas a través de dispositivos móviles (98\%) y hacen un uso promedio de casi dos horas diarias. No solo los usuarios se benefician de estas tendencias de crecimiento, sino también las empresas, que intentan sacarle el máximo partido a este desarrollo. A medida que el número de usuarios activos crece de manera constante, también lo hace el de empresas que utilizan cuentas corporativas en diferentes plataformas de redes sociales como una herramienta de marketing. En este contexto, las compañías han ido cambiando sus contenidos en las distintas plataformas online para adaptarse al surgimiento de otros formatos de contenido, especialmente el de video. Muchas marcas de moda han reinventado sus estrategias de marketing y negocios para adecuarse y acercarse a mercados emergentes, por lo que el marketing digital se convierte en una herramienta imprescindible para la comunicación de las marcas con sus públicos, principalmente los más jóvenes (Kapferer y Bastien, 2012; Segarra-Saavedra y Frutos-Amador, 2018). En este escenario, el marketing digital cobra importancia a la hora de beneficiar en el conocimiento de la marca, la interacción del consumidor y las motivaciones de compra.

En el actual entorno empresarial moderno, e impulsado por el crecimiento de plataformas en línea, el video como herramienta de marketing presenta muchas ventajas. Precisamente, se ha convertido en una opción de marketing innovadora, potenciada por la tecnología y la elección del cliente (Sedej, 2019). Específicamente, que la industria de moda haya tenido que adaptarse a un mundo digital para mejorar su posicionamiento y competitividad, ha implicado la necesidad de implantar nuevas tecnologías y técnicas como el videomarketing para optimizar sus estrategias de mercadeo. En este sentido, este artículo tiene como objetivo analizar el uso de la estrategia de videomarketing por parte de las empresas de moda, para entender el enfoque en el desarrollo de esta estrategia, y las posibles diferencias y similitudes entre empresas posicionadas en las categorías de moda de lujo y moda accesible.

Existen estudios que han analizado las estrategias de marketing de empresas del sector de la moda (González Romo y Plaza Romero, 2017; Alonso González, 2015; Caerols Mateo y de la Horra Veldman, 2015); otros que han enfocado su análisis en la comunicación de las marcas en algunas redes sociales, o en la categorización del posicionamiento de la marca en el sector de lujo o de lifestyle (Navarro-Beltrá et al., 2020; Arbaiza Rodriguez y Huertas García, 2018); otros que centran su análisis desde la perspectiva de generación del storytelling y creatividad (Segarra-Saavedra y Frutos-Amador, 2018); o bien desde la visión de la participación de los usuarios en los contenidos generados por las marcas y el rol de los influencers (Amendola et al., 2018; Geissinger y Laurell, 2016; Sanz Marcos et al., 2020).

No obstante, el uso efectivo de técnicas de videomarketing y sus diferentes tipologías no ha sido un tema de investigación ampliamente explorado. Asimismo, con el contexto de la pandemia de la Covid19, también ha adquirido importancia conocer las innovaciones de las marcas a la hora de trabajar diferentes tipologías de contenido de video y con qué tipo de objetivo y función.

\section{El uso del video en estrategias de marketing}

Según el estudio de las tendencias digitales para el año 2021 de IAB España (IAB Spain, 2021), el video es el formato estrella que utilizan las firmas para conectar con la audiencia. Según IAB, las empresas lucharán contra la saturación publicitaria integrando cada vez más a la marca en los propios videos. El formato live streaming o trasmisiones en vivo ha sido uno de los más populares durante la pandemia de la Covid19, logrando generar una relación más cercana de las marcas con su audiencia. Las tendencias del estudio de 
IAB España también mencionan el crecimiento en el uso de videos explicativos animados, que son bastante cortos y ayudan a describir cómo funciona un producto o servicio, y en los cuales muchas veces se utiliza el humor para resaltar alguna característica. El videomarketing puede considerarse dentro de la tipología del marketing de contenidos (Costa-Sánchez, 2017), y según Miller (2011), los objetivos del contenido en una estrategia de video son informar, entretener y educar.

Asimismo, algunos estudios (Costa Sánchez, 2014; Gómez-Pérez y Pérez-Rufí, 2013; Garrido Pintado y Fernández-Fernández, 2014) han analizado e identificado que cuando se utilizan videos en marketing y comunicación, los principales contenidos audiovisuales empleados por las marcas pueden ser de diferentes tipos, como por ejemplo el host video (recibe al usuario en las webs de las empresas y busca informar sobre sus productos y servicios); videos de producto y servicios (ofrecen una narrativa visual a la hora de explicar las características del producto, con impacto superior a fotos y texto); videos tutoriales (son un subtipo dentro de la categoría de videos de productos y servicios, que se centran en solucionar dudas, demostrar su uso y persuadir a la compra); videos testimoniales o de entrevistas (su principal objetivo es generar confianza y humanizar a las marcas, y son útiles a la hora de proporcionar información de una empresa, alejada de la perspectiva comercial); branded content informativo (busca ofrecer contenido que sea del interés del usuario y lograr ser un referente en un tema en el sector en el cual opera la empresa); videos de identidad corporativa (se caracterizan por contenidos relacionados con las felicitaciones en fechas señaladas, como navidad, eventos corporativos, etc.); videos de responsabilidad social corporativa (participación de la empresa en campañas de solidaridad, medio ambiente o diferentes tipos de interés de la sociedad, alejados de las finalidades de venta); y videos publicitarios (buscan claramente trabajar el conocimiento de la marca, de sus productos y servicios, con la finalidad de impactar e persuadir al consumidor).

Varios autores (Meerman Scott, 2015; Mowat, 2018; Bortone y Shankman, 2017) han identificado el video como una de las mayores oportunidades para atraer nuevos clientes de una manera real y auténtica. El videomarketing presenta oportunidades para que las empresas evoquen emociones y atraigan las necesidades de sus audiencias (Sedej, 2019), y muchos autores coinciden en que el videomarketing es una parte esencial de la comunicación de marketing en el entorno empresarial moderno (Krämer y Böhrs, 2017).

\section{El videomarketing en la industria de la moda}

Estudios que han examinado las estrategias de marketing digital en la industria de la moda han centrado su enfoque en diferentes perspectivas. Alonso González (2015) en su análisis del uso de herramientas online por parte de firmas como El Corte Inglés, Mango y Zara, ha indicado que la comunicación de las marcas a través de las redes sociales como Twitter, Facebook, Instagram y Pinterest ayudan a generar un discurso positivo, participativo y generador de comunidades de marca con los públicos de interés. Navarro-Beltrá y col. (2017) focalizaron su estudio en el uso de Twitter por parte de las marcas H\&M, Zara, Ralph Lauren y Hugo Boss, identificando que estas no aprovechan el potencial dialógico que ofrece esta red social para relacionarse con sus seguidores, ya que su principal actividad es la comunicación de imágenes, noticias y novedades. Según el estudio de Bug y Heene (2020), que se centra en analizar las estrategias de marketing de las firmas de moda en Instagram, el contenido de los videos depende en gran medida de la categoría de la marca. La mayoría de las empresas publican videos con imágenes; por una parte, aquellas con posicionamiento más accesible se enfocan en videos de productos, y, por otra parte, aquellas otras encuadradas en el segmento de lujo y premium más bien utilizan los videos para contar una historia sobre la moda, la calidad y el origen del producto. 
Algunos estudios se han centrado en analizar las estrategias de marketing en la moda de lujo (González Romo y Plaza Romero, 2017; Brun y Castelli, 2013; Kapferer y Bastien, 2012; Sanz Marcos et al., 2020). Según Kapferer y Bastien (2012) las modas de lujo se centran en la utilización de estrategias de presencia online mediante websites y redes sociales que propician la interacción con el usuario, para generar acercamiento e impulsar la participación en el desarrollo del storytelling de la marca. Mediante estrategias de storytelling, las compañías buscan mostrar los procesos de creación de sus colecciones, su historia, sus fundadores, sus trabajadores actuales, la procedencia de sus materiales, mostrar sus desfiles y eventos, mostrar la realidad de los backstages, etc. (Zahaira et al., 2017). Por otra parte, Navarro-Beltrá et al. (2020) han analizado estrategias de contenido digital de firmas de moda de lujo y de moda rápida en la plataforma Facebook, identificando que las marcas en estas categorías comparten similitudes, como predominio de imágenes y pocos vídeos. Finalmente, Martínez Sala et al. (2019) en su análisis de la comunicación digital de Zara en Facebook, han identificado que, pese a un crecimiento importante en el uso de vídeos en esta plataforma, es inferior al de los posts con imágenes, siendo la mayoría del tipo de contenido relacionado con la comunicación y promoción de sus productos.

Otras investigaciones se han centrado en estudiar a plataformas como Youtube (Lavalle-Amaya y Atarama Rojas, 2016), donde se ha identificado que los contenidos con más éxito (en vistas y likes) son aquellos que no están directamente relacionados con la moda, sino que ayudan al usuario a solucionar problemas de belleza o aportan consejos (tips); aunque en algunos casos, también se pueden mostrar prendas o atuendos para obtener una mayor visibilidad del producto. También en Youtube, el estudio de Bug et al. (2020) identificó que los tipos de video más utilizados por las marcas de moda fueron el de testimoniales, el de colocación de producto, y videos de campañas y documentales. Estos autores indican que el uso de estrategias de marketing en esta plataforma varía según el sector, por ejemplo, las marcas deportivas cuentan más con videos de testimonios para ofrecer la imagen de marca, mientras que las firmas de lujo suelen utilizar contenido de videos behind the scenes para informar a su grupo objetivo. Sin embargo, el alcance del marketing de video a través de un canal de YouTube de marca se ha identificado como no tan elevado, comparado con otras plataformas.

Segarra-Saavedra y Frutos-Amador (2018) mencionan que el uso del videomarketing y el branded content, como herramientas de la comunicación persuasiva online, busca un acercamiento al nuevo usuario como creador de contenidos, que representa un público cada vez más segmentado y diverso. Específicamente, en cuanto al análisis de la aplicación de videomarketing, Caerols Mateo y de la Horra Veldman (2015) analizaron el formato publicitario denominado fashion film, mediante el análisis de piezas - que combinan el contenido audiovisual con la moda y las redes sociales - que fueron seleccionadas por el Madrid Fashion Film Festival. Díaz Soloaga y García Guerrero (2016) han demostrado que los fashion films representan una oportunidad extraordinaria en términos de construcción de marca, ya que permiten la comunicación de una amplia gama de valores y sentimientos universales como el amor, libertad, honestidad, traición, lealtad, odio, etc., buscando crear y mantener una profunda conexión con los públicos a través de las narraciones audiovisuales online. El storytelling es una de las estrategias clave en el marketing digital y móvil, principio que se encuentra en estrategias de videomarketing, redes sociales, eventos y exposiciones abiertas al público, que buscan interactuar con la audiencia y mostrar su historia (Zahaira et al., 2017).

Según los resultados del estudio comparativo del uso de videomarketing en diferentes sectores (CostaSánchez, 2017), la industria de la moda actualiza de manera poco frecuente sus contenidos audiovisuales y los autores indican que las marcas analizadas emplean los videos como una estrategia pensada para generar conversión y ventas, sin la intención de trabajar otra tipología de contenido audiovisual como identidad 
corporativa, aspectos de valores o responsabilidad social. En este sentido, la investigación de Teona y col. (2020) profundiza en el uso de videos publicitarios con apelación a la sostenibilidad por parte del sector de la moda, tanto en marcas dentro de la categoría de lujo como de fast-fashion, identificando que los usuarios prefieren publicidad en video que usa afirmaciones sustantivas sobre sostenibilidad (¿cómo se produce de manera sostenible un producto?), en lugar de asociativas (la marca no está directamente relacionada con la iniciativa sostenible) tanto en firmas de lujo como de moda rápida. Además, las afirmaciones sustantivas ofrecen un mayor beneficio a las marcas de lujo a la hora de generar actitud positiva hacia estas.

Según Rees-Roberts (2020), algunas marcas de moda optarán por formatos cinematográficos más tradicionales, como videos de narrativa corta, mientras que otras experimentarán con narrativas visuales transmitidas en vivo. De igual modo, el mismo autor indica que con el creciente impacto económico de las redes sociales, las marcas de moda han pasado de ser simples casas de diseño a ser estudios más híbridos que producen tanto productos materiales como contenido digital, incorporando el video de manera más completa en sus estrategias de comunicación de marca.

En este contexto, esta investigación pretende conocer qué técnicas de videomarking están llevando a cabo las marcas del sector de la moda según su categoría, analizando qué enfoque de formato vídeo están aplicando dentro de sus estrategias de marketing digital. Se pretenden identificar los aspectos más relevantes en la comunicación de las marcas a través del uso del videomarketing, analizando si existen también diferencias respecto a ambos sectores (lujo y económico) según si son ya estables en el mercado comparado con las de reciente creación. Asimismo, se busca entender las principales tendencias que las marcas han empleado mediante el uso de vídeo durante el periodo de confinamiento por la pandemia de la Covid19, a la hora de comunicarse con su audiencia.

Se plantan las siguientes preguntas de investigación:

- ¿En qué plataformas se observa un mayor uso de la técnica de videomarketing por parte de las empresas en la categoría lujo y accesible?

- ¿Qué posibles diferencias se pueden identificar entre las categorías de empresas sobre el tipo de inversión de vídeo y mensaje que se quiere transmitir en el uso de videos?

- $\quad$ ¿Se observan nuevas tendencias de video por parte de las empresas durante el confinamiento por la pandemia de la Covid19?

\section{Metodología}

La metodología utilizada es la cualitativa dado que el objetivo del estudio es conocer qué aspectos más relevantes en el uso del videomarketing diferentes empresas del sector de la moda han utilizado para comunicarse con su audiencia. Por las necesidades del estudio se realiza un enfoque del análisis de contenido (Piñuel Raigada, 1995; Berganza Conde y Ruiz San Román, 2005). La metodología de análisis de contenido facilita la aplicación sistemática de unas reglas fijadas previamente, y que sirvan para medir la frecuencia con que aparecen unos elementos de interés en el conjunto de una masa de información, que se ha seleccionado para estudiar algunos de los aspectos que se creen útiles a los propósitos de la investigación (Berganza Conde y Ruiz San Román, 2005). Para Piñuel Raigada (1995) en el análisis de contenido se pueden usar técnicas de medida que pueden ser cuantitativas o cualitativas basadas en la comparación de categorías mediante el uso de fichas o unidades de análisis, con el objetivo de producir datos relevantes que contribuyan a interpretar correctamente los contenidos analizados. 


\section{Selección de las marcas de moda y plataformas de redes sociales}

El estudio se centra en marcas dirigidas mayoritariamente a mujeres, de entre una franja de edad de 20 a 50 años. Los criterios de selección de la muestra han tenido en cuenta dos aspectos: por un lado, el posicionamiento de la marca en la categoría de moda de lujo o moda accesible, y, por otro lado, la antigüedad de las firmas en la industria de la moda (más de 40 años o menos de 20 años). Ver Figura 1 para selección de las marcas.

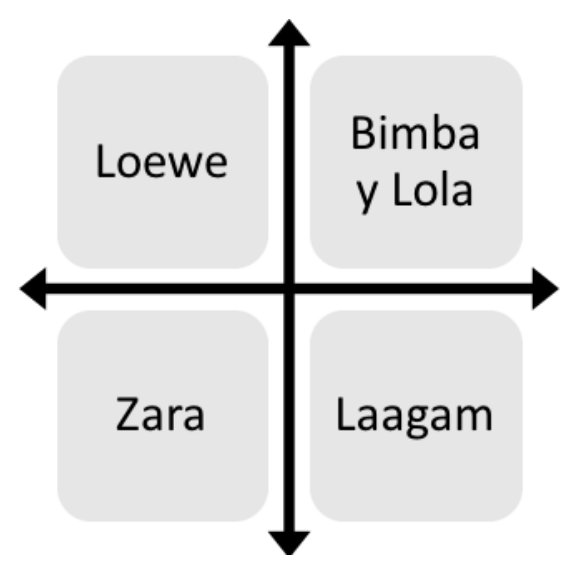

Figura 1. Selección de las marcas examinadas en el estudio Fuente: Elaboración propia

Las marcas con presencia estable de ambos sectores, Loewe y Zara, son las llamadas retailers, ambas creadas en un principio para su comercio en tiendas físicas, pero que a lo largo de los años han tenido que ir introduciéndose en el canal online para no perder su competitividad. Por otro lado, las pure players, Bimba y Lola y Laagam, se caracterizan por ser marcas de moda ya nacidas en la red y con la implementación de nuevas tecnologías desde sus inicios. En la tabla 1 se proporciona una visión general de las marcas seleccionadas arriba mencionadas.

Tabla 1. Visión general de la muestra: marcas retailers y pure players

\begin{tabular}{ll}
\multicolumn{1}{c}{ MARCA } & \multicolumn{1}{c}{ Visión general } \\
\hline LOEWE & $\begin{array}{l}\text { Es una casa de moda española de lujo creada por Heinrich Roessberg Loewe el año } \\
\text { 1846 que presenta colecciones basadas en el arte contemporáneo y vanguardista. }\end{array}$ \\
\hline ZARA & $\begin{array}{l}\text { Cadena de moda que pertenece al grupo Inditex, fundada en 1974 que tiene por } \\
\text { objetivo ofrecer moda atractiva a un amplio público internacional y que responde } \\
\text { rápidamente a los cambios de demanda y gustos. }\end{array}$ \\
\hline LAAGAM & $\begin{array}{l}\text { Es una marca nativa digital de moda femenina creada en 2016 por Inés Arroyo que } \\
\text { presenta prendas versátiles para diferentes ocasiones. Busca el empoderamiento de la } \\
\text { mujer a través de la vestimenta. }\end{array}$ \\
\hline BIMBA Y & $\begin{array}{l}\text { Es una marca que ha crecido rápidamente tanto en el mercado español como en el } \\
\text { internacional. Fue fundada en 2005 por las hermanas Uxía y María y presentan } \\
\text { diseños contemporáneos y lujosos accesibles. }\end{array}$ \\
\hline
\end{tabular}

Fuente: elaboración propia 
La elección de Facebook, Instagram y Youtube como plataformas objeto de estudio se ha debido a que son redes muy diferenciadas que deben abordarse desde concepciones muy distintas y se tenía el objetivo de conocer cómo las marcas de moda en diferentes posicionamientos enfocan sus estrategias de videomarketing en cada una de ellas. Asimismo, según el estudio anual de redes sociales de IAB Spain (2020), Facebook sigue siendo la red más conocida de forma espontánea (como en ediciones pasadas), seguida de Instagram, que sigue creciendo año tras año, Twitter, WhatsApp y YouTube. WhatsApp se mantiene como la red social con más usuarios, seguida de Facebook, YouTube y Instagram. Por tanto, se ha seleccionado las tres redes sociales con mayor número de usuarios en España. Se ha descartado WhatsApp, por las características de esta red social a la hora de poder seleccionar los contenidos publicados por las marcas y la interacción de los mismos con las audiencias.

\section{Análisis de contenidos. Variables y medición}

El estudio abarca las publicaciones de las marcas durante un período de seis semanas entre abril y mayo de 2020, que coinciden con la fase de confinamiento por la pandemia de la Covid19 en España. Concretamente, las seis semanas analizadas comprenden las siguientes etapas: Semana 1 (S1) = 13 a 19 abril 2020; S2= 20 a 26 abril 2020; S3= 27 abril a 3 mayo 2020; S4= 4 a 10 mayo 2020; S5= 11 a 17 mayo 2020; S6= 18 a 24 mayo 2020. La declaración del estado de alarma en España ha sido oficializada a mitad del mes de marzo de 2020. Así que hemos optado por centrar el análisis con inicio un mes después de la declaración del estado de alarma, examinando la frecuencia de publicación durante seis semanas consecutivas, para poder verificar las respuestas de las marcas y sus posibles adaptaciones de contenido.

Para la aplicación del análisis de contenido, se han establecido unas categorías de análisis en base a las tipologías, características y formatos de video identificados en la revisión teórica; y también en relación a la presencia de las marcas en plataformas online (tipo de redes sociales, número de suscriptores, frecuencia de publicación, tipología de post (imagen, video), tipología de video y mensaje, y utilización de hashtags). De esta manera, los contenidos (categorías) vienen determinados en función de la temática o lo que se pretende analizar con los mismos. Por tanto, para cada red social, se ha establecido una serie de categorías, adaptadas a las características de cada plataforma. Ver Tabla 2 para las categorías de análisis aplicadas en relación al canal estudiado.Una vez definido el proceso de metodológico empleado, así como las variables de análisis se procederá a un análisis de los resultados obtenidos con objetivo de posteriormente discutir sobre las preguntas de investigación planteadas.

\section{Resultados y Discusión}

\section{Plataformas con más visibilidad en el uso de la técnica de videomarketing}

En relación a la totalidad de publicaciones, se puede observar en la Tabla 3 que todas las marcas utilizan en las plataformas analizadas la técnica de videomarketing, aunque la marca Bimba y Lola es la que presenta una mayor frecuencia en todas las plataformas. Se observa la tendencia de una mayor continuidad de publicaciones de contenidos en formato imagen. Instagram ha sido la plataforma que más versatilidad ha proporcionado en el uso técnicas de videomarketing, especialmente por el empleo de posts de videos fijos o en formato IGTV, aunque estos siguen siendo inferiores a los de imágenes tanto en Facebook como en Instagram. Estos resultados coinciden en parte con Martínez Sala et al. (2019), que reconocen el crecimiento del uso de videos por parte de Zara en Facebook, aunque en menor cantidad comparado con las publicaciones de imágenes. 
Tabla 2. Categorías analizadas en relación al canal estudiado

\begin{tabular}{|c|c|c|c|}
\hline \multirow{2}{*}{\begin{tabular}{|c|c|} 
Categorías \\
Presencia en redes sociales
\end{tabular}} & \multicolumn{3}{|c|}{ Variables de análisis } \\
\hline & Facebook & & \\
\hline & Instagram & & \\
\hline & Youtube & & \\
\hline \multirow{21}{*}{$\begin{array}{c}\text { Característica de la } \\
\text { estrategia en cada canal }\end{array}$} & Instagram & Número de fans & \\
\hline & & $\begin{array}{c}\text { Frecuencia de } \\
\text { publicación semanal }\end{array}$ & \\
\hline & & Post de Imagen & \\
\hline & & Post de video & Total \\
\hline & & & Fijo \\
\hline & & & IGTV \\
\hline & & Uso de hashtags \# & \\
\hline & Facebook & Número de fans & \\
\hline & & $\begin{array}{c}\text { Frecuencia de } \\
\text { publicación semanal }\end{array}$ & \\
\hline & & Post de Imagen & \\
\hline & & Post de video & Duración media \\
\hline & & & Tipología \\
\hline & & & Mensaje \\
\hline & & & $\begin{array}{c}\text { Presencia de } \\
\text { retransmisión en } \\
\text { directo o stories }\end{array}$ \\
\hline & & Uso de hashtags \# & \\
\hline & Youtube & $\begin{array}{l}\text { Número de } \\
\text { suscriptores }\end{array}$ & \\
\hline & & $\begin{array}{c}\text { Frecuencia de } \\
\text { publicación semanal }\end{array}$ & \\
\hline & & Video & Duración media \\
\hline & & & Tipología \\
\hline & & & $\begin{array}{l}\text { Mensaje y } \\
\text { descripción }\end{array}$ \\
\hline & & Uso de hashtags \# & \\
\hline
\end{tabular}

Fuente: elaboración propia

Tabla 3. Presencia de video en las plataformas sociales

\begin{tabular}{lccccc}
\hline & \multicolumn{2}{c}{ INSTAGRAM } & \multicolumn{2}{c}{ FACEBOOK } & YOUTUBE \\
\hline & $\begin{array}{c}\% \\
\text { presencia } \\
\text { VÍDEO }\end{array}$ & $\begin{array}{c}\text { \% } \\
\text { presencia } \\
\text { IMAGEN }\end{array}$ & $\begin{array}{c}\% \\
\text { presencia } \\
\text { VÍDEO }\end{array}$ & $\begin{array}{c}\text { \% } \\
\text { presencia } \\
\text { IMAGEN }\end{array}$ & $\begin{array}{c}\mathbf{N}^{\mathbf{T}} \text { Total de } \\
\text { vídeos }\end{array}$ \\
\hline LOEWE & $22,0 \%$ & $78,0 \%$ & $11,5 \%$ & $88,5 \%$ & 1 \\
\hline BIMBA Y LOLA & $40,9 \%$ & $59,1 \%$ & $26,5 \%$ & $73,5 \%$ & 7 \\
\hline LAAGAM & $27,9 \%$ & $72,1 \%$ & - & - & 4 \\
\hline ZARA & $25,5 \%$ & $74,5 \%$ & $12,7 \%$ & $87,3 \%$ & 4 \\
\hline
\end{tabular}

Fuente: elaboración propia 
Tipologías, mensajes y tendencias de videomarketing por parte de las empresas durante el confinamiento por la pandemia del Covid19

Como se puede observar en la Tabla 4, Loewe hizo uso de IGTV durante todas las semanas del periodo analizado. De los contenidos de video, el $50 \%$ se trataba de videos de más larga duración publicados en el apartado de IGTV. En la Figura 2 se puede ver la predominancia del contenido alrededor de la temática "LOEWE EN CASA", donde se añadió el hashtag \#StayAtHome aprovechando el contexto del confinamiento por la Covid-19. Los videos se componen de un conjunto de mini series de eventos y talleres en línea que son transmitidos a través de Instagram Live, y posteriormente publicados en IGTV (íntegra o parcialmente). En estos videos, que pueden tener una duración de entre 3 hasta 33 minutos, se exploran distintos estudios de artistas (expertos en pintura, en la combinación de artesanía y técnicas textiles tradicionales en la elaboración de esculturas), que dan a conocer sus obras, los procesos que utilizan para elaborar sus productos, qué materiales son claves para su elaboración y recomendaciones clave.

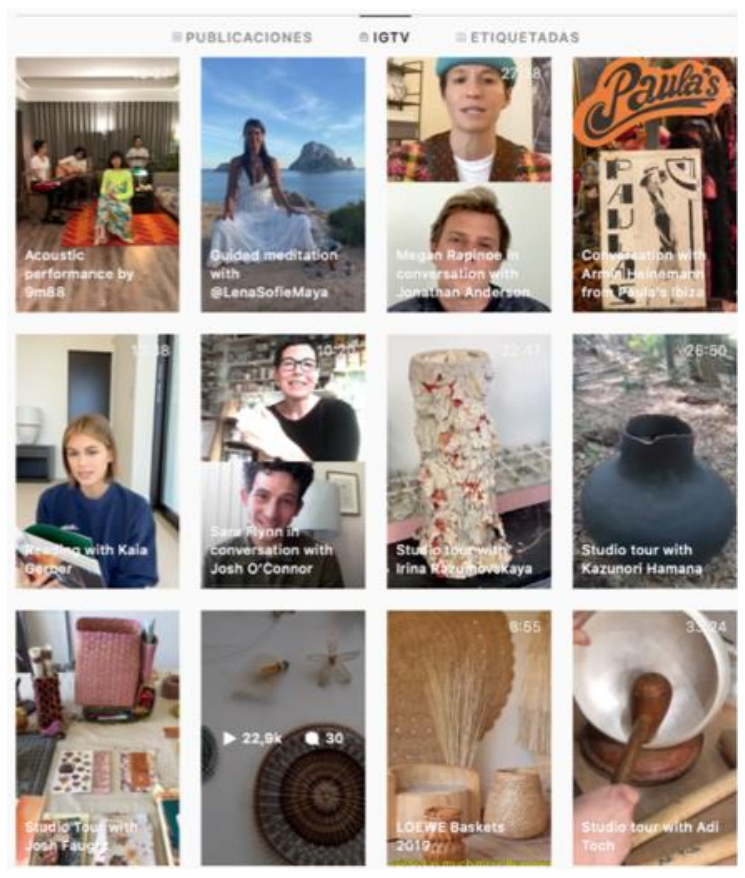

Figura 2. Captura de Instagram de Loewe sesión IGTV Fuente: Cuenta Instagram @loewe https://www.instagram.com/loewe/channel

En el periodo correspondiente a las últimas semanas examinadas, Loewe también ha añadido otros formatos de IGTV como shows en directo, donde artistas no reconocidos cantan utilizando prendas de su colección, y clases de meditación. En la Tabla 4 también se observa por parte de Loewe el uso de los posts de videos fijos, que cuentan con una duración máxima de 60 segundos. En este tipo de post, predomina el formato Making of y tutoriales, donde enseñan paso por paso cómo se crean los bolsos: Ballong Bag, Puzzle Bag, Barcelona Bag, etc. (Ver Figura 3). Igualmente cuentan con videos introductorios y presentaciones de los nuevos artistas (Ver Figura 4), contenidos a los que se añaden posteriormente el hashtag \#StayHome. 
Tabla 4. Estrategia digital en Instagram

\begin{tabular}{|c|c|c|c|c|c|c|c|}
\hline \multirow[t]{2}{*}{ Canal Instagram } & \multirow[b]{2}{*}{$N^{0}$ de fans } & \multirow[b]{2}{*}{$\begin{array}{c}\text { Frec. } \\
\text { Pub. } \\
\text { semanales }\end{array}$} & \multirow[b]{2}{*}{$\begin{array}{l}\text { Post de } \\
\text { imágenes }\end{array}$} & \multicolumn{4}{|c|}{$\begin{array}{c}\text { Tipo de } \\
\text { vídeo }\end{array}$} \\
\hline & & & & $\begin{array}{c}\text { Post } \\
\text { de } \\
\text { vídeos }\end{array}$ & Fijo & IGTV & $\begin{array}{l}\text { Uso } \\
\text { de \# }\end{array}$ \\
\hline \multirow{6}{*}{$\begin{array}{l}\text { LOEWE } \\
\text { (@loewe) }\end{array}$} & \multirow[t]{6}{*}{2.100 .000} & (S1) 21 & 15 & 6 & 4 & 2 & Sí \\
\hline & & (S2) 19 & 15 & 4 & 1 & 3 & Sí \\
\hline & & (S3) 21 & 15 & 6 & 4 & 2 & Sí \\
\hline & & (S4) 18 & 16 & 2 & 1 & 1 & Sí \\
\hline & & (S5) 22 & 16 & 6 & 2 & 4 & Sí \\
\hline & & (S6) 17 & 15 & 2 & 1 & 1 & Sí \\
\hline \multirow{6}{*}{$\begin{array}{l}\text { BIMBA Y LOLA } \\
\text { (@ bimbaylola) }\end{array}$} & \multirow[t]{6}{*}{873.000} & (S1) 7 & 4 & 3 & 3 & 0 & Sí \\
\hline & & (S2) 7 & 7 & 0 & 0 & 0 & Sí \\
\hline & & (S3) 5 & 1 & 4 & 4 & 0 & Sí \\
\hline & & (S4) 9 & 2 & 7 & 5 & 2 & Sí \\
\hline & & (S5) 8 & 6 & 2 & 1 & 1 & Sí \\
\hline & & (S6) 8 & 6 & 2 & 2 & 0 & Sí \\
\hline \multirow{6}{*}{$\begin{array}{l}\text { ZARA } \\
\text { (@ zara) }\end{array}$} & \multirow[t]{6}{*}{39.400 .000} & (S1) 20 & 14 & 6 & 3 & 3 & Sí \\
\hline & & (S2) 3 & 2 & 1 & 1 & 0 & Sí \\
\hline & & (S3) 3 & 1 & 2 & 2 & 0 & Sí \\
\hline & & (S4) 6 & 6 & 0 & 0 & 0 & Sí \\
\hline & & (S5) 12 & 11 & 1 & 1 & 0 & Sí \\
\hline & & (S6) 7 & 4 & 3 & 3 & 0 & Sí \\
\hline \multirow{6}{*}{$\begin{array}{l}\text { LAAGAM } \\
\text { (@laagam }\end{array}$} & \multirow[t]{6}{*}{109.000} & (S1) 7 & 5 & 2 & 1 & 1 & No \\
\hline & & (S2) 8 & 6 & 2 & 1 & 1 & No \\
\hline & & (S3) 7 & 4 & 3 & 1 & 2 & No \\
\hline & & (S4) 8 & 5 & 3 & 1 & 2 & $\mathrm{No}$ \\
\hline & & (S5) 7 & 6 & 1 & 0 & 1 & No \\
\hline & & (S6) 6 & 5 & 1 & 0 & 1 & No \\
\hline
\end{tabular}

Nota: *S1 (Semana 1), S2 (Semana 2), y a continuación

Fuente: elaboración propia 

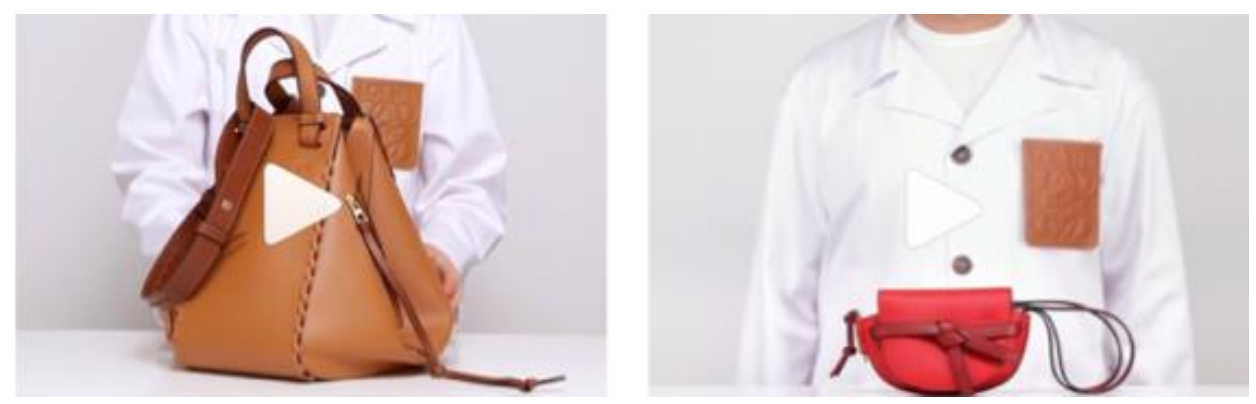

Figura 3. Captura de Instagram Loewe making of

Fuente: Cuenta Instagram (@loewe) https://www.instagram.com/loewe/

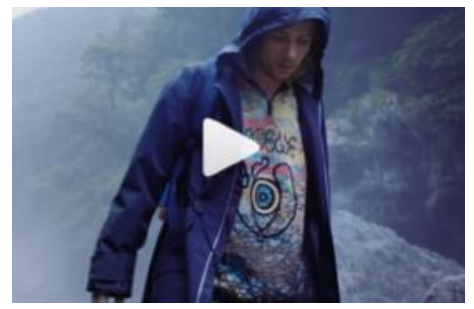

Figura 4. Captura de Instagram Loewe de la presentación del artista invitado Josh O'Connor Fuente: Cuenta Instagram (@loewe)https://www.instagram.com/loewel

También se ha identificado el uso de imágenes por parte de las marcas con la intención de contar su historia a través de fotografías antiguas de sus tiendas y colecciones. Asimismo, se ha verificado el uso publicitario mediante filmes animados, donde predominan temas como la vitalidad, celebraciones, y unión entre subculturas. Se ha podido observar que con los videos en directo o IGTV de \#StayAtHome, publicados por la marca Loewe, se explotaba a una audiencia de fans bastante importante en todo el mundo. La firma ha buscado asociarse con artistas (conocidos y no conocidos y emergentes), trabajando conceptos como la estética, el diseño y la creatividad. Al ser videos en directo, la cámara sigue al artista que muestra los rincones de sus talleres u obras, explorando y asociando los atributos de la marca (diseño, estética, creatividad, exclusividad).

En cuanto a Bimba y Lola, de la tipología de los contenidos de videos, el 83,3\% se refieren a posts fijos y el 16,7\% son de IGTV. Se puede observar en la Tabla 4 que la mayoría del contenido de marca publicado en el canal Instagram durante el periodo analizado va dirigido a mostrar nuevas colecciones (Home Party y Hot bag), de forma indirecta, ya que los contenidos de video son protagonizados por la modelo Diane Guais que lleva distintos looks de la marca sin hacer referencia directa a estos. En la comunicación de la colección Home Party emplea un estilo de video que fusiona ediciones VHS y retro, donde predomina el atributo "I'm inviting myself. This is a party for me" (ver Figura 5.) 

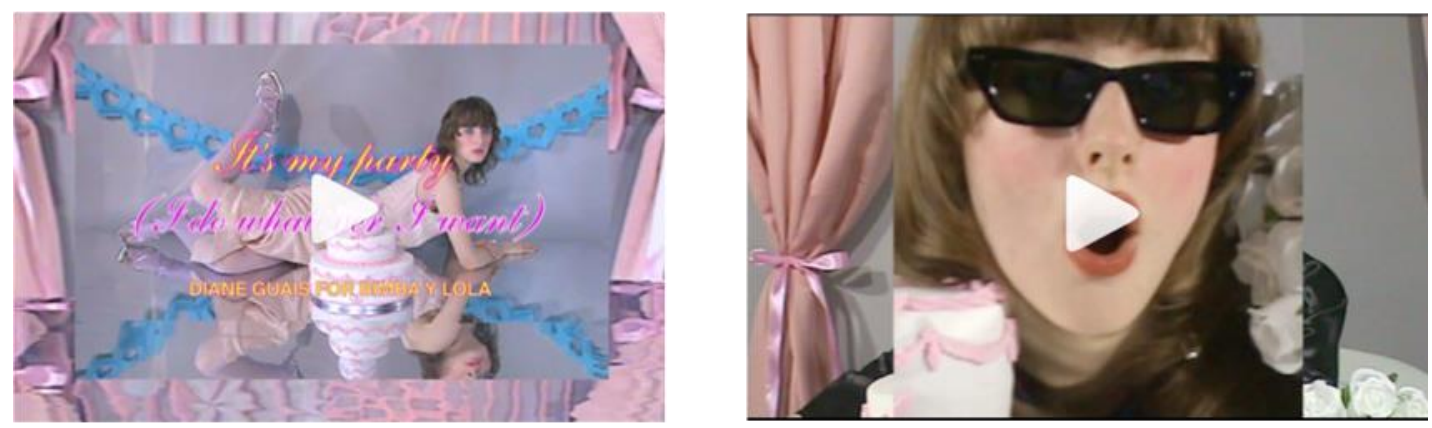

Figura 5. Captura del Instagram Bimba y Lola post vídeo fijo Home Party Fuente: Cuenta BIMBA Y LOLA Instagram (@bimbaylola) https://www.instagram.com/bimbaylolal

En la comunicación de la colección A Hot Bag, formada por tres videos principales dirigidos por la artista denominada PZTODAY, se exploran enfoques fuera de lo convencional. Lily Mcnemany, Lera Abova y la propia PZTODAY son las protagonistas de esta campaña, centrada en la nueva colección de bolsos de Bimba y Lola. Aunque los tres videos son totalmente diferentes, se centran en los mismos atributos utilizando esta frase: El verano y el calor están cerca, y tu bolso lo sabe \#thisisHOT, para explorar la colección de verano (ver Figura 6). Son campañas que apelan al humor, enseñando diferentes situaciones en que un producto de la marca puede solucionar un problema o una situación incómoda. BIMBA Y LOLA utiliza posts fijos para publicar videos de corta duración o para hacer avances de videos más largos (superiores a 60 segundos), que posteriormente son publicados en su totalidad en IGTV.
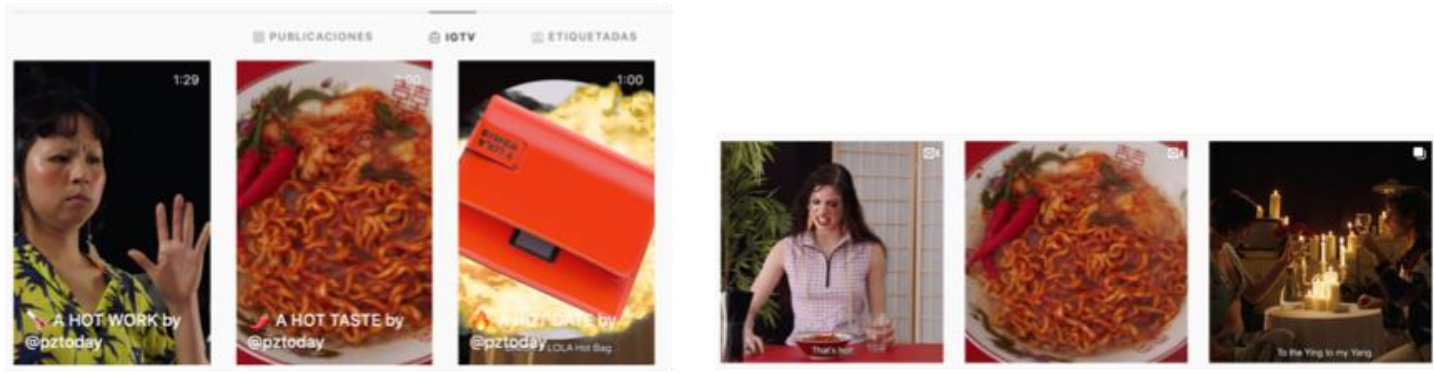

Figura 6. Captura del Instagram Bimba y Lola sección IGTV y post fijo Hot Bag

Fuente: Cuenta BIMBA Y LOLA Instagram (@bimbaylola) https://www.instagram.com/bimbaylola/channel/ https://www.instagram.com/bimbaylolal

De igual modo, dentro de los contenidos analizados en los posts fijos, ha empleado el hashtag \#thisishot, utilizando la apelación musical y el marco de realización en formato de animación, donde la base son flores con caras que cantan (ver Figura 7). Con este tipo de contenido, Bimba y Lola hace partícipes a los usuarios con el título "FLOWERS, MUSIC AND LOVE", proponiéndoles que cojan el video y elijan su persona y flor favoritas, y finalmente que añadan su canción preferida. Asimismo, la marca ha trabajado en posts fijos, videos informativos al público sobre la apertura de sus tiendas después del periodo de cierre por el confinamiento (Ver Figura 8). Tanto los videos fijos como los de la sesión IGTV son de índole publicitaria, 
que buscan mostrar sus colecciones explorando atributos de estética y diseño, a través de formatos originales y poco convencionales. Con esta línea editorial, la marca busca consolidar un acercamiento a la generación Y y Z.
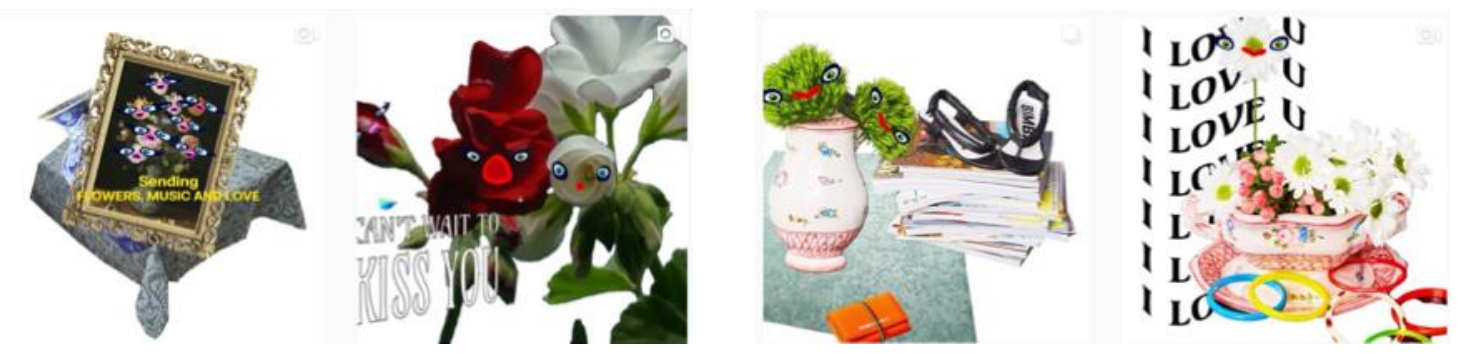

Figura 7. Captura del Instagram Bimba y Lola sección flores

Fuente: Cuenta BIMBA Y LOLA Instagram (@bimbaylola) https://www.instagram.com/bimbaylolal
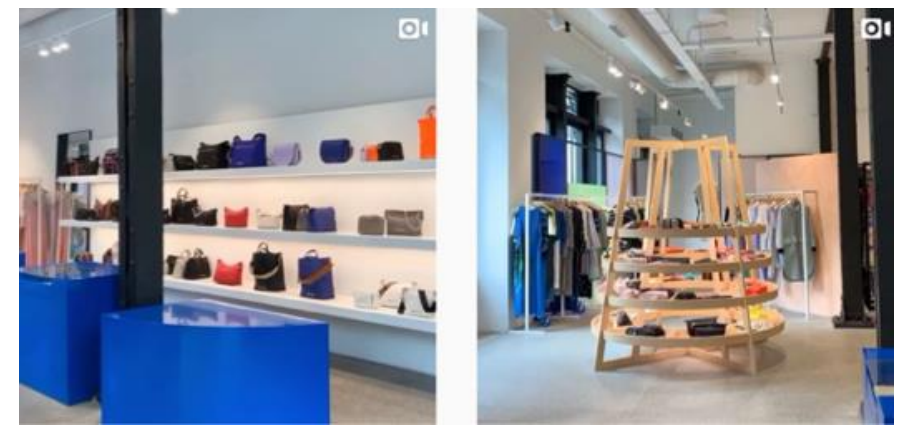

Figura 8. Captura de Instagram Bimba y Lola de videos informativos sobre la apertura de tiendas Fuente: Cuenta BIMBA Y LOLA Instagram (@bimbaylola) https://www.instagram.com/bimbaylolal

Zara, a la hora de trabajar su contenido en el canal Instagram se ha centrado únicamente en contenidos publicitarios relacionados con sus nuevas colecciones. De la tipología de videos publicados, el 76,9\% son fijos y el 23,1\% son de IGTV. La marca emplea modelos anónimos para promocionar su nueva colección Spring Summer Collection, que ofrece una segmentación entre kids, man y woman. Los contenidos son publicados en formato de post fijo y IGTV de la campaña completa (ver Figura 9). En cuanto a los posts fijos (ver Figura 10), se publican videos cortos de modelos anónimos usando siempre prendas de la nueva colección en situaciones cotidianas (en casa leyendo, paseando, bailando, limpiando, etc.).Zara en el apartado \#ZaraMan publicó 3 videos seguidos (el mismo contenido dividido en 3 episodios), en una sección llamada Face to Face, donde se hablaba con el actor y director Benn Northover mediante la creación de un video retrato, en el cual se exploraban varios aspectos de su personalidad (ver Figura 11). En general, los contenidos que publica la marca son de tipo publicitario, con empleo de la utilización de modelos anónimos y mediante la apelación musical (no hay argumentos ni diálogos por parte de los actores/modelos). El objetivo es enseñar las prendas de las nuevas colecciones que están categorizadas por temáticas y géneros. 

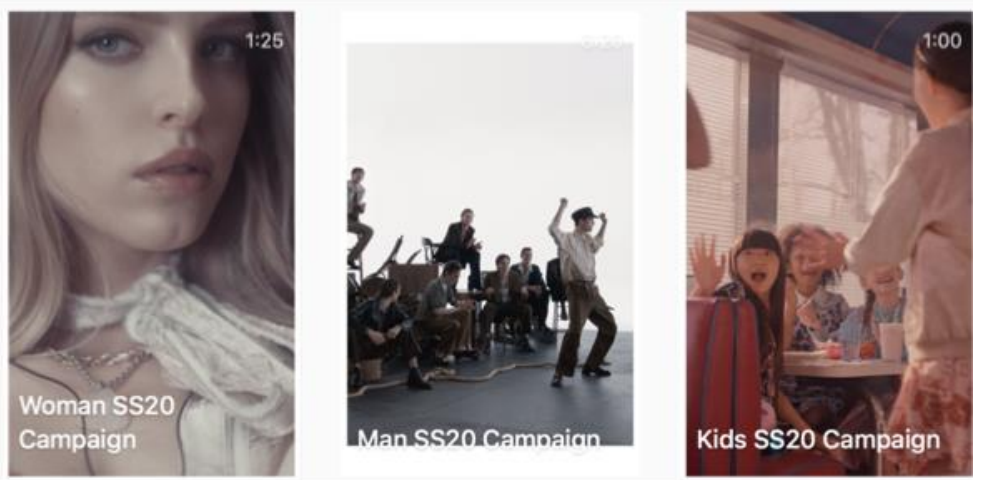

Figura 9. Captura de Instagram de ZARA de la sección IGTV Fuente: Cuenta Zara Oficial (@zara) https://www.instagram.com/zara/channel/
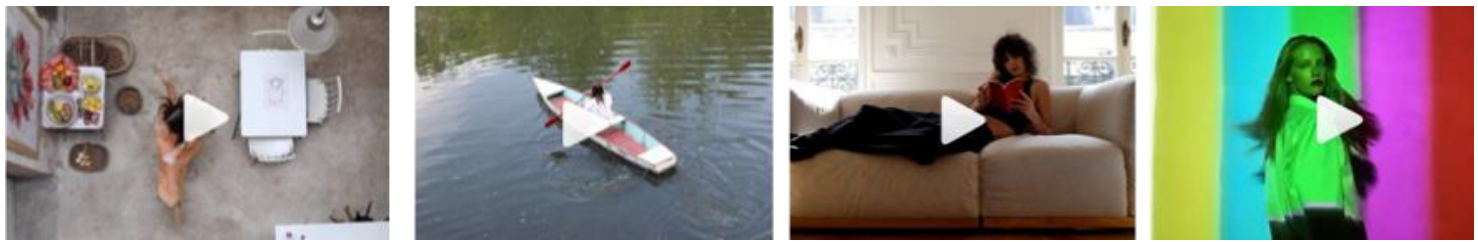

Figura 10. Captura de Instagram de ZARA de la sección post fijo Fuente: Cuenta Zara Oficial (@zara)https://www.instagram.com/zaral
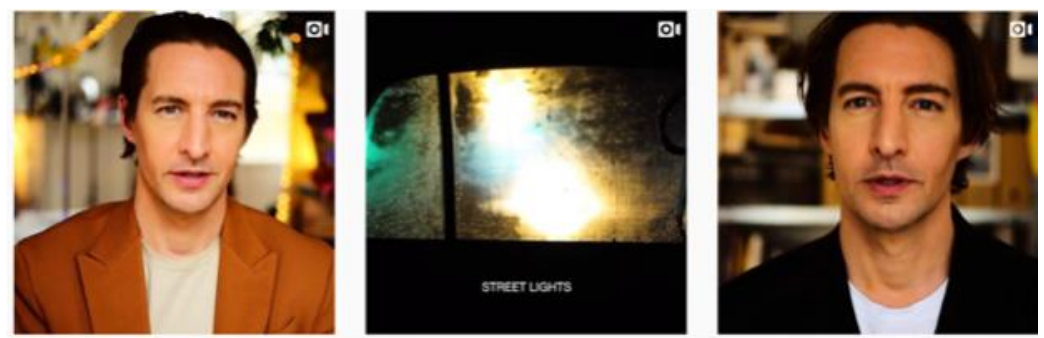

Figura 11. Captura de Instagram de ZARA de la sección post fijo con Benn Northover (Video series Face to Face). Fuente: Cuenta Zara Oficial (@zara) https://www.instagram.com/zaral

En cuanto a Laagam, del total de las publicaciones dentro de la tipología de videos, el 33,33\% se caracterizaban por posts fijos y el $66,66 \%$ por contenido de IGTV. Es la marca que utiliza más el formato IGTV. En los posts fijos, los videos cortos muestran modelos utilizando sus prendas con música de fondo (ver Figura 12). En cambio, en los IGTV publican video-learnings, video-tutoriales y video-formativos (ver Figura 13), que exploran la estética y la versatilidad del diseño de las prendas, la calidad de los materiales, 
y también aspectos relacionados con la creación de moda sostenible. Asimismo, los contenidos de los videos buscan resaltar los valores de la empresa. La observación de la estrategia de publicación de la marca durante el periodo analizado demuestra que se ha centrado en videos más informales o caseros, mediante el uso de formatos tutoriales o informativos, con el objetivo de establecer una relación más cercana con el usuario, haciéndole copartícipe y cocreador en los videos, así como en la resolución de dudas que este pueda tener a la hora de adquirir una prenda. Por otro lado, la compañía también ha desarrollado contenido no directamente relacionado con ella, como videos con celebraciones de fechas importantes (día de la madre) o mostrando valores de la marca (sostenibilidad o consumir y viajar localmente). En cuanto al uso de Facebook (ver Tabla 5), no existe la misma cantidad de publicaciones que en Instagram (Tabla 4), debido a las características de cada plataforma. Cuando Instagram añade en una publicación seis fotografías, en la cuenta de Laagam aparece visualmente una fotografía, la primera escogida por la marca; mientras que, en Facebook, se exponen todas las fotografías añadidas. Es por eso que el número de imágenes es superior en la cuenta de Facebook, aun tratándose del mismo contenido.
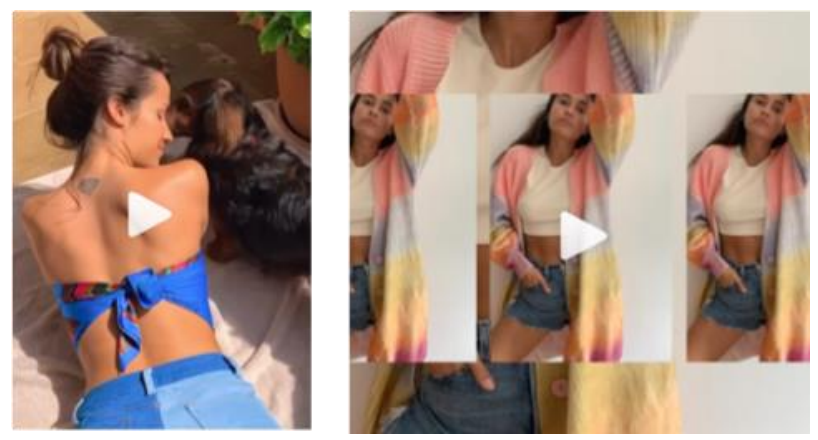

Figura 12. Captura de Instagram de LAAGAM de la sección post fijo

Fuente: Cuenta Instagram Laagam (@laagam ) https://www.instagram.com/laagam $/ ? h l=e n$

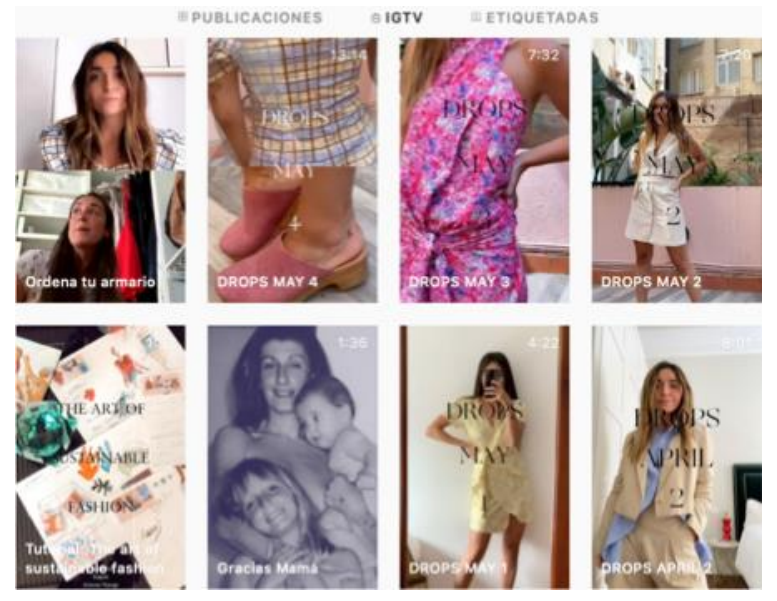

Figura 13. Captura de Instagram de Laagam de la sesión IGTV

Fuente: Cuenta Instagram Laagam (@laagam https://www.instagram.com/laagam /channel/?hl=en 
Tabla 5. Estrategia digital en Facebook

\begin{tabular}{|c|c|c|c|c|c|}
\hline FACEBOOK & $N^{0}$ de fans & $\begin{array}{c}\text { Total } \\
\text { publicaciones } \\
\text { semanales }\end{array}$ & $\begin{array}{c}\text { Total } \\
\text { publicaciones } \\
\text { imágenes }\end{array}$ & $\begin{array}{c}\text { Total } \\
\text { publicaciones } \\
\text { videos }\end{array}$ & $\begin{array}{c}\text { Uso de } \\
\text { hashtags } \\
\#\end{array}$ \\
\hline LOEWE & \multirow[t]{6}{*}{632.000} & 35 & 29 & 6 & Sí \\
\hline \multirow{5}{*}{ @ LOEWE } & & 32 & 30 & 2 & Sí \\
\hline & & 15 & 11 & 4 & Sí \\
\hline & & 17 & 15 & 2 & Sí \\
\hline & & 15 & 15 & 0 & Sí \\
\hline & & 16 & 15 & 1 & Sí \\
\hline \multirow{6}{*}{$\begin{array}{l}\text { BIMBA Y LOLA } \\
@ \text { BimbayLolaOfficial }\end{array}$} & \multirow[t]{6}{*}{651.000} & 7 & 5 & 2 & Sí \\
\hline & & 13 & 12 & 1 & Sí \\
\hline & & 6 & 3 & 3 & Sí \\
\hline & & 8 & 2 & 6 & Sí \\
\hline & & 6 & 6 & 0 & Sí \\
\hline & & 9 & 8 & 1 & Sí \\
\hline \multirow{6}{*}{$\begin{array}{l}\text { ZARA } \\
\text { @Zara }\end{array}$} & \multirow[t]{6}{*}{28.000 .000} & 36 & 34 & 2 & No \\
\hline & & 3 & 2 & 1 & No \\
\hline & & 3 & 1 & 2 & No \\
\hline & & 6 & 6 & 0 & No \\
\hline & & 8 & 8 & 0 & No \\
\hline & & 7 & 4 & 3 & No \\
\hline \multirow[t]{6}{*}{ LAAGAM } & \multirow[t]{6}{*}{ ND } & ND & \multirow{6}{*}{\multicolumn{3}{|c|}{$\begin{array}{l}\text { Dejó de utilizar la cuenta Facebook en } \\
2018\end{array}$}} \\
\hline & & ND & & & \\
\hline & & ND & & & \\
\hline & & ND & & & \\
\hline & & ND & & & \\
\hline & & ND & & & \\
\hline
\end{tabular}

Fuente: elaboración propia 
En relación a las diferencias y similitudes de tipología de video y de objetivo de mensaje, hemos podido constatar que Laagam (marca asequible y pure player) ha publicado contenidos de video caracterizados como más informales o caseros, donde se muestran formatos tutoriales o explicativos de sus prendas, resolviendo mayoritariamente dudas que normalmente los usuarios se plantean a la hora de adquirir una de sus prendas, y/o cómo utilizarlas o combinarlas. Por una parte, la firma trabaja con contenidos relacionados con sus productos, pero, por otro lado, también añade contenido ajeno a la marca, por ejemplo, desarrollando branded content relacionado con el día de la mujer, donde hace referencia a su filosofía del empoderamiento de la mujer en el mundo. Estos resultados refuerzan la tendencia de contenidos de videos vinculados con la función de información y educación (Miller, 2011) y también con la facilitación de información para proporcionar soluciones a problemas o consejos a los usuarios (Lavalle-Amaya y Atamara Rojas, 2016).

Si nos centramos en Loewe, en cuanto al análisis del contenido argumental de los videos en Facebook, se observa la misma tipología analizada previamente en las publicaciones de Instagram; y los contenidos de texto y uso de hashtags que acompañan a los posts de video también son los mismos en ambas redes sociales, los cuales se clasifican en las siguientes categorías:

- $\quad$ General: \#LOEWE, \#LOEWEarchives, \#LOEWEprojects

- $\quad$ Por productos realizados: \#PuzzleBag, \#BalloonBag, \#LOEWEperfumes

- $\quad$ Por colecciones o eventos: \#LOEWESS20, \#LOEWEPaulas

- $\quad$ Actualidad: \#StayHome

- $\quad$ Días importantes: \#WorldBookDay

Si observamos a Bimba y Lola, los textos que acompañan a los videos en Facebook son más escuetos, ya que la marca emplea una descripción más detallada en Instagram. En esta se añade, por ejemplo, quiénes son los que han maquillado al modelo para el video, el responsable de estilismo, maquillaje, dirección, etc., detalles que agradan y llaman la atención de la mayoría de usuarios de la cuenta de la empresa. No obstante, se advierten que las fechas de publicaciones, el uso de la tipología de video y tendencia de contenidos analizados en Facebook coinciden totalmente con las publicaciones en la cuenta de Instagram. En cuanto al empleo de hashtags, identificamos el uso de la categoría relacionada con colecciones o eventos (\#BIMBAYLOLALoves, \#Thisishot).

En relación a Zara, se observa que los contenidos de texto que acompañan a los videos son similares en ambas redes sociales. En Facebook los videos, que en Instagram son considerados posts fijos de menor duración, no añaden el nombre de la modelo, pero sí incluyen la referencia directa a la página web de la marca. Por ejemplo, en el caso de los videos de Ben Northover (Figura 11), al hacer clic al link, se descubre que hay tres partes más, en total 6 videos. En la cuenta de la firma en Instagram se incorporan hashtags como por ejemplo \#Zarawoman, \#Zaracampaign, no obstante, no se añaden el uso de hashtags en la cuenta de Facebook. Durante en el periodo de estudio se ha podido observar la presencia de nuevas publicaciones de video en los canales de Youtube de las cuatro marcas examinadas. Concretamente, en relación a las marcas con posicionamiento en la categoría lujo, en la cuenta de Youtube de Loewe podemos identificar una única publicación que se caracteriza por un contenido publicitario de la campaña "LOEWE Paula's Ibiza 2020" (ver Figura 14). Es un filme grabado en Nueva Delhi que busca comunicar vitalidad y versatilidad de las prendas de la marca con un reportaje animado. Los protagonistas son capturados en fiestas privadas, montando en scooters, en rincones de la capital, y en otras diferentes situaciones. También se incluye el comunicado que donará 40 euros por cada producto vendido en las tiendas y web LOEWE de esta colección (Paula's Ibiza) a proyectos educativos para niños afectados por la COVID-19 entre abril y agosto de 2020. 


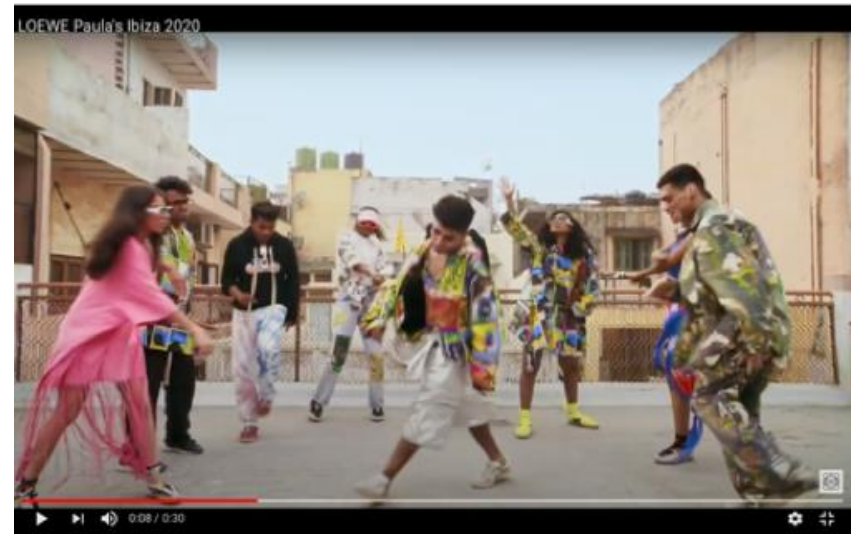

Figura 14. Captura de pantalla publicación YouTube Loewe (LOEWE Paula's Ibiza 2020) Fuente: Canal Loewe Youtube. https://www.youtube.com/channel/UCIkFEXV_zvjOlmOcKEHW_hg

Los videos en el Canal Youtube de Bimba y Lola trabajan campañas publicitarias a través del uso de un storytelling original, y buscan transmitir una nueva visión de la marca y consolidar una línea más cercana a las generaciones Y y Z. Los cuatro primeros videos publicados (ver Figura 15) de la campaña "Holiday Celebration", dirigidos por Marçal Forés (una serie de cuatro capítulos que cuentan una historia futurista), se basan en una invasión de bimbaders (cuatro misteriosos invasores pertenecientes al universo digital, que la ilustradora alemana Friedericke Hantel creó para la marca). Estos invasores son: la osa BAF, el gato BOH, el perro LOM y la mona LIS, que son personajes inspirados en la nostalgia por la estética SCI-FI. Cada personaje representa una personalidad e identidad muy específica, que se busca asociar a la identidad de la marca: joven, moderna y futurista. Los otros videos publicados (serie de tres episodios), dirigidos por la artista PZToday, mencionan al nuevo bolso de la marca: "A Hot bag" (ver Figura 16), en los cuales el bolso "Hot" de Bimba y Lola se convierte en el gran salvador que conseguirá templar la situación cuando el calor se intensifique.

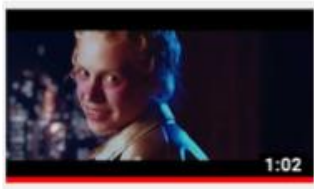

CALLING ALL BIMBADERS | Holiday Celebration.

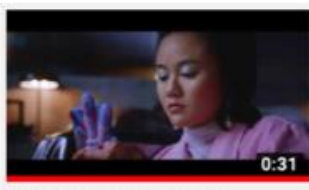

BIMBADERS INVASION | Holiday Celebration.

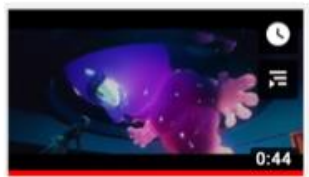

BIMBADERS INVASION II! Holiday Celebration.

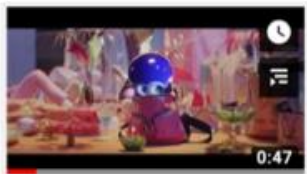

BIMBADERS INVASION III | Holiday Celebration.

Figura 15. Captura de Youtube de Bimba y Lola (Campaña Holiday Celebration)

Fuente: Canal Bimba y Lola Youtube. https://www.youtube.com/channel/UCLv3sIbQM6R8VlBWfqmVuOQ 


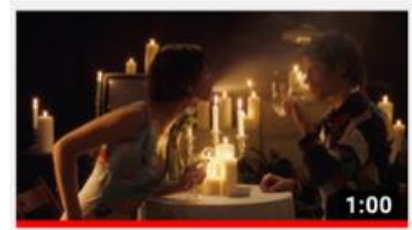

HOT DATE I \#thisisHOT by PZ Today

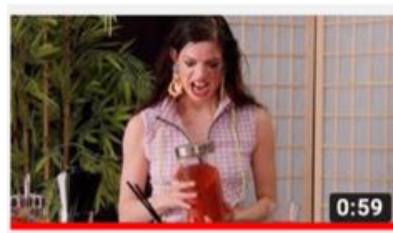

HOT TASTE | \#thisisHOT by PZ Today

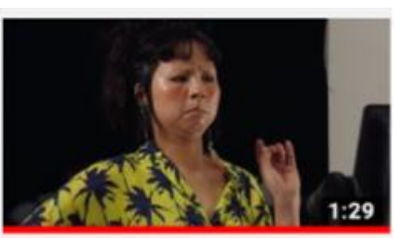

HOT WORK | \#thisisHOT by PZ Today

Figura 16. Captura de Youtube de Bimba y Lola (Campaña a Hot Bag)

Fuente: Canal Bimba y Lola Youtube. https://www.youtube.com/channel/UCLv3sIbQM6R8VlBWfqmVuOQ

Bimba y Lola (categoría de lujo y pure player) desarrolla el contenido en redes sociales en dos bloques. Por un lado, trabaja con videos publicitarios para promover sus productos, en los cuales emplea una estética e hilo argumental originales, extravagantes y poco convencionales. Por otro lado, trabaja con videos de identidad corporativa, donde emplean historias informativas sobre el modo en que la marca ha ido evolucionando a lo largo de los años. Asimismo, utilizan videos testimoniales relacionados con contenidos de gente referente del sector de la moda. En cuanto a los videos publicitarios, se desarrollan a través de series con storytelling. La estética de las historias tiene la función de fomentar una visión nueva de la firma, dirigida a un público más joven (generación Y y Z). También en la promoción de sus productos, la marca emplea videos en formato blog, con relatos inspirados en escenas behind the scene, o making of, con el objetivo de dar a conocer al equipo que esta detrás de estas historias. Estos resultados coinciden con la tendencia de tipologías de videos analizadas por otros estudios (Costa Sánchez, 2014; Garrido Pintado y FernándezFernández, 2014), y, además, nuestra investigación demuestra que existe la prevalencia de la tipología de videos publicitarios o de producto y servicios, seguidos de videos de branded content informativo.

En cuanto a Laagam, dos videos pertenecen a la categoría ruido dazz (videos de tipología de identidad de marca, pero también de transmisión de información útil para los espectadores y suscritores, donde se muestran los valores que quiere transmitir la firma como branded content informativo y se comunica información especializada y útil ajena a la marca) (ver Figura 17). Están en una sección donde periódicamente Laagam realiza podcasts, en los cuales se escuchan hablar a mujeres independientes e inspiradoras. Se busca asociar las prendas de la marca a las mujeres empoderadas. Estos podcasts son publicados en formato de audio en la web y son retransmitidos en directo en Youtube donde se guardan posteriormente. Los usuarios pueden intervenir si tienen alguna pregunta. En este caso se hace una entrevista en directo a Blanca Suárez (Ruido Dazz 20), fundadora de la firma de moda: Bleïs Madrid, y a Elena Gual (Ruido Dazz 21), artista y pintora. Los otros dos videos publicados (ver Figura 18) son clasificados en la categoría de productos y servicios, tutoriales e informativos. En el video "Brazer \& Pants Creme" se enseña cómo queda la prenda, se facilitan consejos y trucos para poder llevarla, ideas de combinaciones, características del tejido, textura, entre otros. Y en el caso del video "Cortando Jeans", se trata de un tutorial en el que se explora la versatilidad de los pantalones, facilitando ideas para diferentes usos de las prendas.

Estos resultados refuerzan los aspectos discutidos por Bug, Winter y Zillikens (2020) en su análisis de la plataforma Youtube, aunque cabe resaltar que nuestros resultados presentan una combinación de diferentes formatos y la emergencia de la tipología del contenido de ruido dazz, que busca la conexión con la audiencia mediante contenidos relacionados con el empoderamiento y la moda. 

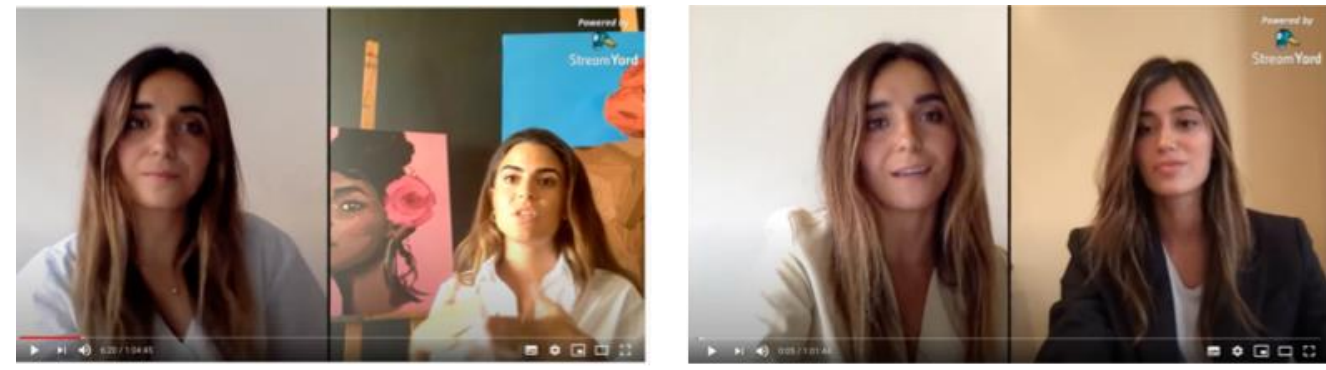

Figura 17. Captura de Youtube de Laagam (Ruido Dazz)

Fuente: Canal Laagan Youtube. https://www.youtube.com/c/laagam/featured

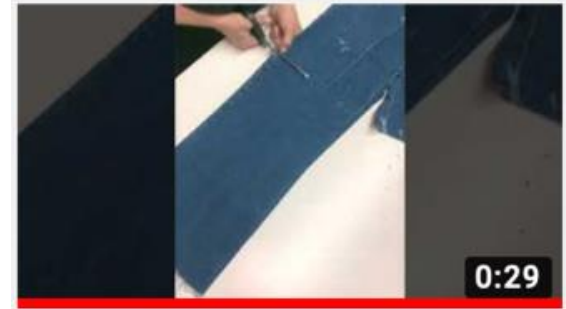

CORTANDO JEANS

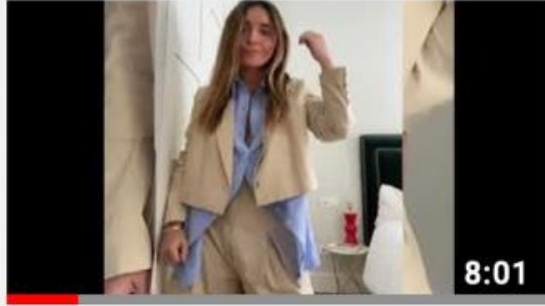

BLAZER \& PANTS CREME

Figura 18. Captura de Youtube de Laagam (Ropa)

Fuente: Canal Laagan Youtube. https://www.youtube.com/c/laagam/featured

Al analizar a Zara (ver figura 19), se puede observar que las cuatro publicaciones son videos publicitarios de las nuevas colecciones (Spring Summer 2020). Estas publicaciones se dividen por temáticas enfocadas en el género: campaña Kids, Woman y Man.
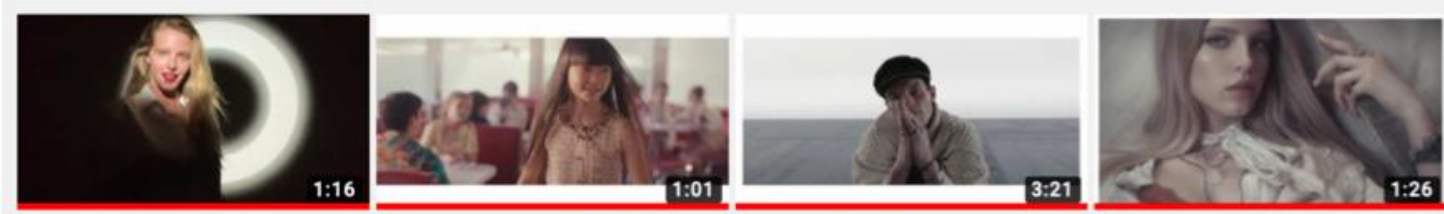

ZARA Spring Summer

ZARA | Kids Campaign Spring

Summer 2020

ZARA | Man Campaign Spring

Summer 2020

ZARA I Woman Campaign

Spring Summer 2020

Figura 19. Captura de YouTube de las campañas de Zara

Fuente: Canal Zara Youtube. https://www.youtube.com/channel/UCa8RD6FJLllG4nBskvhOGZw 
Los resultados han reflejado que las marcas con una presencia más reciente en el mercado (pure players), y posicionadas en diferentes categorías (de lujo y de moda asequible), presentan similitudes en los mensajes que quieren transmitir con sus estrategias de video, buscando generar una relación más cercana con sus usuarios. Ambas categorías coinciden en el uso de videos publicitarios e informativos, así como en el empleo de storytellings creativos y originales. No obstante, la empresa con posicionamiento en la categoría asequible invierte más en videos tutoriales que la marca situada en la categoría lujo. Estos resultados coinciden con Bug et. al (2020) al evidenciar que hay similitudes en las estrategias utilizadas por las compañías, y que el contenido puede variar según el sector. En nuestros resultados, observamos que la tipología puede diferir según posicionamiento de categoría.

Respecto a las marcas con presencia más duradera en el mercado, Loewe y Zara, utilizan mayoritariamente videos publicitarios con la función de promover sus colecciones de prendas. En el desarrollo de la técnica de videomarketing realizan grandes inversiones en la estética de las escenas, donde cuentan con directores creativos consolidados y fotógrafos profesionales de renombre, aunque también podemos visualizar un mayor uso del enfoque de video publicitario por parte de Zara, en la categoría de moda asequible. Esta última utiliza videos publicitarios, (protagonizados normalmente por modelos anónimos en situaciones cotidianas llevando las prendas de la colección), caracterizados por el empleo de una fuerte estética de la imagen y apelaciones musicales de fondo. Por otra parte, Loewe también se vale de videos con contenidos publicitarios, con una importante inversión en la estética y calidad de las escenas. Se sirve en algunos de sus vídeos de actores conocidos y utiliza un estilo simple y elegante en formatos de videos making off de sus productos. En cuanto a las diferencias de tipo de mensaje, Loewe, en contraste con Zara, genera videos con un mayor contenido vinculado al branded content, promoviendo los valores de la marca asociados con el amor por el arte en general (artesanía, diseños, innovación, etc.). Aunque esta variedad de estrategias de desarrollo de contenido coincide con el estudio de Bug y Heene (2020), nuestros resultados reflejan que, pese a que haya una diferencia en la tipología de formatos y mensajes que las marcas exploran, existe una tendencia cada vez mayor en el empleo de contenidos híbridos, intercambiando contenidos publicitarios de sus productos con contenidos relacionados con otros intereses indirectos de los consumidores.

Las marcas de posicionamiento en la categoría de lujo (Bimba y Lola y Loewe) realizan mayor inversión en la contratación de productoras de vídeo y directores externos, que generan un contenido de video original y de alta calidad estética. Igualmente, cuentan con colaboraciones de artistas conocidos enfocados al perfil y valores que las marcas quieren transmitir. Laagam, con un posicionamiento en la categoría de moda asequible, emplea menos equipos externos de producción de video y dirección artística. En cuanto a Zara, su inversión se centra en videos de estética refinada y simple, aunque sobresale la utilización de modelos anónimos que muestren bien las prendas, por eso la mayoría de los videos son grabados en estudios con fondos lisos, en interiores o en paisajes poco saturados para que la prenda sea el foco principal.

A raíz de la situación provocada por el coronavirus y declarado el estado de alarma en España a mitad del mes de mayo de 2020, las firmas de ropa se han visto obligadas a cancelar sesiones de fotos, grabaciones de campañas en el exterior, entre otros problemas. En este contexto, los resultados demuestran que algunas de las marcas estudiadas han adaptado sus contenidos de video a la nueva situación, creando contenidos relacionados con la pandemia, con el entretenimiento y con los valores de la marca. Específicamente, se observan algunas diferencias en tendencias de contenido por parte de las marcas posicionadas en diferentes categorías. Ambas marcas posicionadas en la categoría de lujo han generado contenidos más relacionados con la pandemia. Loewe ha sido la única que ha mencionado directamente en sus contenidos de video la situación de la pandemia, mediante el lanzamiento de la campaña "Loewe en casa". La marca ha tratado 
contenidos con un enfoque de entretenimiento y usado videos sobre sus diferentes productos, siempre recordando la importancia de quedarnos en casa, a través de la exploración del hashtag \#stayathome.

También es interesante observar que para su colección de verano, la marca ha lanzado la campaña "Paula`s Ibiza 2020" (mes de mayo 2020), donde emplea imágenes de fiestas en exteriores, que muestran las ganas de sus usuarios de disfrutar de escenarios exteriores, después de casi dos meses de confinamiento. Asimismo, la marca ha usado videos de contenidos corporativos relacionados con la responsabilidad social corporativa, vinculando una campaña de donación, de un porcentaje de las compras de las prendas de la colección de primavera-verano 2020, a familias y niños víctimas de la situación de emergencia social y económica surgida durante la pandemia de la Covid19. Estos resultados contrastan con Costa-Sánchez (2017), lo que evidencia que las marcas de moda no solamente están empleando el videomarketing para la generación de conversión, sino que también existe una tendencia creciente en el uso de videos de contenidos de identidad corporativa y de responsabilidad social.

Bimba y Lola ha mencionado la situación de la pandemia de una forma indirecta, que se constata al analizar su campaña "Home party", en la cual explora mediante videos diferentes maneras de disfrutar de uno mismo estando en casa. También emplea videos sobre sus productos, y videos informativos con consejos para adaptar las compras en sus tiendas físicas en un contexto de pos-confinamiento. Al igual que Loewe, Bimba y Lola, a la hora de promover su colección de verano, también ha empleado en sus videos imágenes festivas con su campaña "Holiday celebrations" (mayo 2020), explorando las necesidades de disfrutar de entornos exteriores por parte de los consumidores.

En cuanto a las marcas posicionadas en la categoría moda asequible, mencionan menos el contexto de la pandemia (Laagam), o no lo consideran (Zara). Laagam alude indirectamente a la pandemia al desarrollar los conceptos de sostenibilidad y localidad en el consumo. Concretamente, la marca recuerda en sus vídeos cómo trabajan la sostenibilidad en el desarrollo de sus productos y la importancia de consumir o viajar localmente. Estos resultados coinciden con el uso de afirmaciones sustantivas sobre prácticas de sostenibilidad de las marcas en relación a sus procesos productivos (Teona et al., 2020), aunque en menor medida comparado con otros tipos de contenidos publicitarios. También ha empleado videos de identidad de marca fortaleciendo su vínculo con el empoderamiento femenino. Los videos tutoriales también han sido una tendencia de la marca, especialmente para entablar una relación más cercana con sus usuarios. En el caso de Zara, aunque algunos de los contenidos de video muestran el uso de sus prendas y productos estando en casa, la mayoría de sus videos con enfoque publicitario exploran escenarios exteriores, recordando sus líneas de producto según género, pero sin relación con la nueva situación y con las restricciones por el confinamiento.

\section{Conclusiones}

Uno de los objetivos del estudio era observar las diferencias en el uso de la técnica de videomarketing entre marcas de moda posicionadas en la categoría de lujo y otras asentadas en la categoría de asequibles. A la hora de seleccionar a las empresas se han tenido en cuenta firmas con larga presencia en el mercado y marcas de creación relativamente reciente, diferenciando a las pure players de las retailers. A la hora de analizar las estrategias de videomarketing utilizadas se examinó si existían diferencias de formatos: de diseño, de mensaje transmitido, de la plataforma donde lo publican, de frecuencia, de técnica y estilo utilizado, etc. 
Los resultados demuestran que Instagram ha sido la plataforma que más versatilidad ha proporcionado, especialmente por la tendencia en formatos de video IGTV, aunque las publicaciones en formato de texto e imágenes siguen siendo las más empleadas. Se identifican que independientemente de la categoría de posicionamiento, existe una tendencia consolidada en el empleo de contenidos híbridos, al combinar la promoción directa de la marca y sus productos, con otros contenidos indirectos, explorando diferentes intereses de la audiencia. También se puede concluir que las marcas con más tiempo de presencia en el mercado español, son las que más contenidos de videos publicitarios han utilizado, en comparación con las marcas pure players, cuyas tendencias de contenidos de sus videos y mensajes están más relacionadas con contenidos caracterizados por ser informales, caseros y con enfoque más relacional.

No se han podido demonstrar en los resultados tendencias innovadoras por parte de las empresas a la hora de comunicarse con la audiencia durante el periodo de la pandemia. Sí que los resultados resaltan que las marcas posicionadas en la categoría de lujo han aprovechado la oportunidad para desarrollar y reforzar los valores de la marca, y también contenidos corporativos relacionados con la responsabilidad social corporativa.

Finalmente, podemos mencionar que, aunque el presente estudio marca pautas que describen las estrategias que algunas de las firmas, posicionadas en las categorías de lujo y de moda asequibles, han empleado para desarrollar sus contenidos de videomarketing durante un periodo específico, centrarse únicamente en cuatro marcas puede ser una limitación a la hora de generalizar los resultados. Y, por tanto, se recomienda para futuras investigaciones la realización de un estudio comparativo más amplio (en marcas y periodo de publicación), especialmente para ampliar el conocimiento de la consolidación de tipologías de contenido de videomarketing complementarias a la perspectiva del video publicitario.

\section{Referencias}

Alonso González, M. (2015). Las redes sociales como canal de comunicación de las marcas de moda españolas. El caso de Zara, Mango y El Corte Inglés. Index.Comunicación: Revista Científica En El Ámbito de La Comunicación Aplicada, 5(1), 77-105.

Amendola, C., Calabrese, M., Caputo, F. y Fabrizio, D.A. (2018). Fashion companies and customer satisfaction: A relation mediated by Information and Communication Technologies. Journal of Retailing and Consumer Services, 43, 251-257. https://doi.org/10.1016/j.jretconser.2018.04.005

Arbaiza Rodriguez, F., Huertas García, S. (2018). Comunicación publicitaria en la industria de la moda: branded content, el caso de los fashion films. Revista de Comunicación, 17(1), 9-33. https://doi.org/10.26441/RC17.12018-A1

Berganza Conde, M. R., Ruiz San Román, J. A. (2005). Investigar en comunicación : guía práctica de métodos y técnicas de investigación social en comunicación. McGraw-Hill Interamericana de España.

Bortone, L., Shankman, P. (2017). Video Marketing Rules: How to Win in a World Gone Video! CreateSpace Independent Publishing Platform.

Brun, A., Castelli, C. (2013). The nature of luxury: A consumer perspective. International Journal of Retail \& Distribution Management, 41(11-12), 823-847. https://doi.org/10.1108/IJRDM-01-2013-0006

Bug, P., Heene, M. T. (2020). Instagram Fashion Videos. En P. Bug (Ed.), Fashion and Film. Moving images and consumer behavior (pp. 113-137). Springer. https://doi.org/10.1007/978-981-13-9542-0_6

Bug, Peter, Winker, C., Zillikens, P. (2020). YouTube Fashion Videos. En Peter Bug (Ed.), Fashion Film. Moving images and consumer behavior (pp. 83-111). Springer. https://doi.org/10.1007/978-981-13-9542-0_5

Caerols Mateo, R., de la Horra Veldman, Y. (2015). Fórmulas creativas en la publicidad de moda. Prisma Social: Revista de Investigación Social, (14), 336-378. 
Costa-Sánchez, C. (2017). Online video marketing strategies. Typology by business sector. Communication and Society, 30(1), 17-38. https://doi.org/10.15581/003.30.1.17-38

Costa Sánchez, C. (2014). La Narrativa Transmedia como aliada de la Comunicación Corporativa: estudio del caso \#Dropped by Heineken . Communication \& Society, 27(3), 127-150.

Díaz Soloaga, P., García Guerrero, L. (2016). Fashion films as a new communication format to build fashion brands. Communication and Society, 29(2), 45-61. https://doi.org/10.15581/003.29.2.45-61

Garrido Pintado, P., Fernández-Fernández, P. (2014). Branded Content \& Storytelling: la distancia más corta entre dos personas es una historia. En S. Liberal Ormaechea \& P. Fernández Perea (Eds.), Últimos estudios sobre publicidad: de 'Las Meninas' a los tuits (pp. 35-48). Fragua.

Geissinger, A., Laurell, C. (2016). User engagement in social media - an explorative study of Swedish fashion brands. Journal of Fashion Marketing and Management, 20(2), 177-190. https://doi.org/10.1108/JFMM-02-2015-0010

Gómez-Pérez, F. J., Pérez-Rufí, J. P. (2013). Nuevos formatos audiovisuales en Internet: cuando el usuario es quien innova. En de Salas Nestares. M. I. \& E. Mira Pastor (Eds.), Prospectivas y tendencias para la comunicación en el siglo XXI (pp. 167-187). Fundación Universitaria San Pablo CEU.

González Romo, Z. F., Plaza Romero, N. (2017). Estrategias de marketing digital en el sector de la moda de lujo. Interacción y redes sociales como herramienta necesaria. Hipertext.Net: Revista Académica Sobre Documentación Digital y Comunicación Interactiva, (15), 17-27. https://doi.org/10.2436/20.8050.01.42

IAB Spain. (2021). Top tendencias Digitales 2021. Recuperado de https://iabspain.es/estudio/top-tendencias-digitales2021/

IAB Spain (2020). Estudio de Redes Sociales 2020. Recuperado de:

https://iabspain.es/estudio/estudio-redes-sociales-2020/

Kapferer, J. N., Bastien, V. (2012). The Luxury Strategy: Break the Rules of Marketing to Build Luxury Brands (2nd Ed.). Kogan Page.

Krämer, A., Böhrs, S. (2017). How Do Consumers Evaluate Explainer Videos? An Empirical Study on the Effectiveness and Efficiency of Different Explainer Video Formats. Journal of Education and Learning, 6(1), 254. https://doi.org/10.5539/jel.v6n1p254

Lavalle-Amaya, G., Atarama Rojas, T. (2016). Youtube como herramienta de marketing estratégico para la moda: Análisis del canal oficial What the chic en el 2015. AdComunica. Revista Científica de Estrategias, Tendencias e Innovación en Comunicación, (12), 91-108. http://dx.doi.org/10.6035/2174-0992.2016.12.6

Martínez Sala, A. M., Segarra-Saavedra, J., y Cristófol Rodríguez, C. (2019). Estrategia de comunicación digital en el sector franquicias de moda. El caso de Zara en Facebook. Área Abierta. Revista de Comunicación Audiovisual y Publicitaria, 19(2), 145-162.

Meerman Scott, D. (2015). The New Rules of Marketing and PR: How to Use Social Media, Online Video, Mobile Applications, Blogs, News Releases, and Viral Marketing to Reach Buyers Directly (5th edition). Wiley.

Miller, M. (2011). YouTube for Business: Online Video Marketing for Any Business (2nd Edition). Que Publishing.

Mowat, J. (2018). Video Marketing Strategy: Harness the Power of Online Video to Drive Brand Growth . Kogan Page.

Navarro-Beltrá, M., García Medina, I., y Miquel-Segarra, S. (2020). Using Facebook as a communication channel in the fashion industry: A comparison of its dialogical side between fast and luxury fashion brands. Palabra Clave, 23(3), e2335-e2335. https://doi.org/10.5294/pacla.2020.23.3.5

Navarro-Beltrá, M., Miquel-Segarra, S., y Medina, I. G. (2017). El uso del potencial dialógico de Twitter: el caso de las marcas de moda. Revista Internacional de Comunicación, 36, 1-14.

Rees-Roberts, N. (2020). After fashion film: social video and brand content in the influencer economy. Journal of Visual Culture, 19(3), 405-421. https://doi.org/10.1177/1470412920964907

Sanz Marcos, P., Pérez Curiel, C., y Velasco Molpeceres, A. M. (2020). Hacia un cambio en el sector de moda y lujo. Del dominio del influencer a la marca: Gucci, Loewe y Margiela. Revista de Comunicación, 19(2), 263-284. https://doi.org/10.26441/RC19.2-2020-A15

Sedej, T. (2019). The role of video marketing in the modern business environment: A view of top management of SMEs. Journal for International Business and Entrepreneurship Development, 12(1), 37-48.

https://doi.org/10.1504/JIBED.2019.103388 
Segarra-Saavedra, J., Frutos-Amador, M. (2018). Creatividad aplicada al videomarketing en Youtube. Análisis del caso de Chanel. Miguel Hernández Communication Journal, 9(1), 101-129. https://doi.org/10.21134/mhcj.v0i9.225

Teona, G., Ko, E., y Kim, S. J. (2020). Environmental claims in online video advertising: effects for fast-fashion and luxury brands. International Journal of Advertising, 39(6), 858-887. https://doi.org/10.1080/02650487.2019.1644144

We are social, \& Hootsuite (2021). Digital 2021. Global Overview Report. The Latest insights into how people around the world use the internet, social media, and ecommerce. Retrieved from https://wearesocial.com/digital-2021

Zahaira, F., González, R., García-Medina, I., y Plaza Romero, N. (2017). Storytelling and Social Networking as Tools for Digital and Mobile Marketing of Luxury Fashion Brands. International Journal of Interactive Mobile Technologies, 11(6), 136-149. https://doi.org/10.3991/ijim.v11i6.7511

Cómo citar este artículo: Torre Reverte, B., \& Girotto, M. (2021). Uso del videomarketing en tiempos de la Covid19: estrategias del sector de la moda. INVURNUS, 16 (1), 1-25. 